\section{Tick-tock: Is your cardiometabolic risk on the clock?}

Diabetes \& Vascular Disease Research 20I4, Vol. II (2) 66-74

(C) The Author(s) 2014

Reprints and permissions:

sagepub.co.uk/journalsPermissions.nav DOI: 10.1 I77/I479|64II3516348

dvr.sagepub.com

(S)AGE

\author{
Robert Stöhr ${ }^{1,2}$, Nikolaus Marx ${ }^{2}$ and Massimo Federici ${ }^{1,3}$
}

\begin{abstract}
Governing a large amount of cellular processes in mammalian cells is a 24-h regulatory mechanism known as the circadian clock. Through the release of neurohormonal factors, the master central clock is able to regulate the otherwise independent peripheral clocks situated in all vital organs. It has recently been shown that forced misalignment of the circadian cycles, often as a consequence of lifestyle factors, is an independent cardiometabolic risk factor and may thus potentially predispose certain groups, such as nightshift workers, to cardiovascular disease. In this review, we will analyse some of the recent advances regarding circadian clock dysfunction and the development of cardiovascular diseases. Finally, we will touch on the developing link between circadian dysfunction and myocardial infarctions.
\end{abstract}

\title{
Keywords
}

Circadian clock, cardiometabolic risk, cardiovascular disease, metabolism

\section{Introduction}

Despite recent decrease in the rates of cardiovascular disease (CVD), this disease was and remains the most common cause of mortality in Europe accounting for $47 \%$ of death in the European Union (EU). ${ }^{1}$ It is estimated that the cost to the EU economy is around 196 billion Euros. ${ }^{1}$ While many risk factors such as smoking, hypertension and hyperlipidaemia have been linked to an increased risk of CVDs, it has only recently been shown that forced misalignment of the behavioural and circadian cycles is an independent cardiometabolic risk factor. ${ }^{2}$ Following this discovery, there have recently been some developments in the field of experimental genetics attempting to elucidate this link between the circadian clock present in different tissues and the occurrence of cardiac and metabolic disease.

In this review, we analyse and summarize some of the milestones that have been made in unravelling this still young field of research of circadian rhythm and its influence on the heart.

\section{Circadian rhythm}

The diurnal variation of light and dark encompassed in the 24-h day has been known for some time to drive many cyclic changes, not only in humans but in nearly all mammalian cells examined to date. ${ }^{3}$ Indeed, the human body is geared to be able to respond to changes in nutrient availability, activity levels and hormonal changes by an internal 24-h clock known as the circadian clock.
This 'clock' is composed of two distinctly separated hierarchical pieces. The central clock located in the suprachiasmatic nuclei of the anterior hypothalamus ${ }^{4}$ commands a peripheral clock present in most vital organs, including heart, liver, muscle, adipose tissue and kidney (reviewed in Dibner et al. ${ }^{5}$ ). While the peripheral clock is mainly influenced through the availability of nutrients (high availability during the day, absent at night) which alter the transcription of key endocrine hormones, ${ }^{5}$ the central clock keeps a master control through its release of neurohormonal factors upon sensing of daylight by the retina $^{6}$ (Figure 1). The main transcription factors involved in this regulation are brain and muscle aryl hydrocarbon receptor (BMAL1) and circadian locomotor output cycles kaput (CLOCK). ${ }^{7,8}$ These transcription factors can heterodimerize and activate their downstream targets which include the Period (Per1, Per2 and Per3) and the cryptochrome (Cryl and Cry2) genes which, further

IDepartment of Systems Medicine, University of Rome Tor Vergata, Rome, Italy

2Medizinische Klinik I, Uniklinik RWTH Aachen, Aachen,

Germany

${ }^{3}$ Center for Atherosclerosis, Policlinico Tor Vergata, Rome, Italy

\section{Corresponding author:}

Massimo Federici, Department of Systems Medicine, University of Rome Tor Vergata, Via Montpellier I, Rome 00133, Italy.

Email: federicm@uniroma2.it 


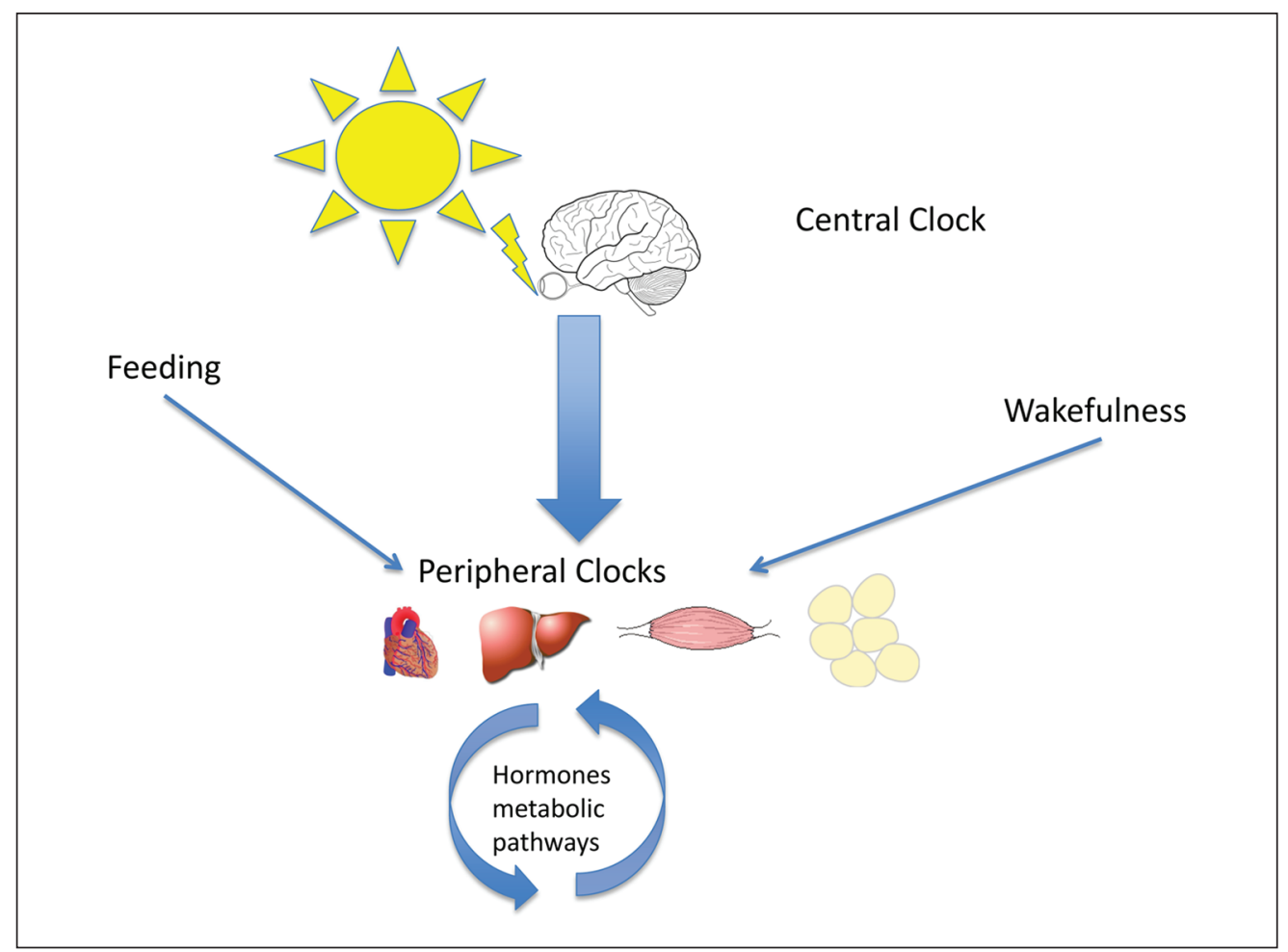

Figure I. Schematic representation of the circadian clock. The central clock located in the suprachiasmatic nuclei of the anterior hypothalamus ${ }^{4}$ is the master switch for the peripheral clocks present in most vital organs including heart, liver, muscle and adipose tissue. The peripheral clock is mainly influenced through the availability of nutrients and the state of wakefulness, which alter the transcription of key endocrine hormones. The central clock keeps a master control through its release of neurohormonal factors upon sensing of daylight by the retina.

to providing further downstream activation, are also responsible for the system regulation through a negative feedback loop ${ }^{9}$ (Table 1). Mice with mutations targeted at either the $C L O C K$ or $B M A L 1$ gene display propensity to develop obesity, hyperglycaemia, hyperlipidaemia as well as increased nitric oxide (NO) synthase uncoupling, suggesting that loss of the normal circadian rhythm may contribute to the development of insulin resistance, obesity and hyperlipidaemia in humans. ${ }^{12,25,26}$

Another important step in unravelling the importance of the internal clock was the demonstration that not only the loss of the central clock elements, such as BMAL1 and CLOCK, but also the loss of their downstream targets, such as PER2, leads to impaired glucose homeostasis and compromised insulin-stimulated NO release independent of obesity in mice. ${ }^{27}$

\section{Circadian clock and cardiovascular function}

The cardiovascular system is a major system under the control of the circadian rhythm. In order for the heart to function continuously, it requires a constant source of energy. Indeed, the heart does not contain a great reserve of adenosine triphosphate (ATP), and its pool is renewed every $10 \mathrm{s.}^{28}$ In the normally functioning heart, ATP is nearly exclusively formed by oxidative phosphorylation (OXPHOS) in the mitochondria. The rate of OXPHOS is balanced to maintain a constant ATP amount by being exquisitely linked to the rate of ATP hydrolysis. ${ }^{29}$ This means that despite higher workloads such as during exercise or stress, the heart maintains a constant amount of ATP. ${ }^{30}$ To achieve this, the heart requires a constant supply of nutrients. It can be considered as being an 'omnivore' as it is able to utilize different energy substrates including fatty acids (FAs), glucose as well as ketone bodies and lactate to generate ATP.

In perfused rat hearts, glucose oxidation rates are increased in hearts isolated during the awake phase with increased expression of GLUT4, increased glycogenolysis and decreased lactate release, ${ }^{31}$ thus suggesting that the heart may have a certain anticipatory function regarding energy substrate availability according to daytime (increased feeding during the awake phase and therefore increased availability of glucose during this time).

\section{Lessons from gene knockout models}

Much of the current knowledge on the clock system has been gained through the study of flies and rodents and may 
Table I. Circadian clock genes and their cardiovascular effects.

\begin{tabular}{|c|c|c|c|c|}
\hline Gene & Abbreviation & $\begin{array}{l}\text { Function in relation of } \\
\text { circadian rhythm }\end{array}$ & $\begin{array}{l}\text { Effect of functional loss on } \\
\text { circadian rhythm }\end{array}$ & $\begin{array}{l}\text { Cardiovascular effects found in } \\
\text { knockout/mutant models }\end{array}$ \\
\hline $\begin{array}{l}\text { Brain and muscle } \\
\text { aryl hydrocarbon } \\
\text { receptor }\end{array}$ & $B M A L I$ & $\begin{array}{l}\text { Heterodimerizes with } \\
\text { CLOCK to activate } \\
\text { downstream targets } \\
\text { including the Per and Cry } \\
\text { genes }\end{array}$ & $\begin{array}{l}\text { Complete loss of circadian } \\
\text { rhythmicity in darkness }\end{array}$ & $\begin{array}{l}\text { Impaired vascular remodelling } \\
\text { following arterial denudation } \\
\text { through impairment of AKT- } \\
\text { eNOS signalling (Anea et al. }{ }^{\prime \prime} \text { ) } \\
\text { Increased superoxide and } \\
\text { endothelial NO synthase } \\
\text { uncoupling in the endothelium }{ }^{12} \\
\text { Loss of diurnal variation of BP } \\
\text { and HR }{ }^{13}\end{array}$ \\
\hline $\begin{array}{l}\text { Circadian } \\
\text { locomotor output } \\
\text { cycles kaput }\end{array}$ & CLOCK & $\begin{array}{l}\text { Heterodimerizes with } \\
\text { BMALI to activate } \\
\text { downstream targets } \\
\text { including the Per and Cry } \\
\text { genes }\end{array}$ & $\begin{array}{l}\text { Knockout unaffected due to } \\
\text { compensation of NPAS2 } 14 \\
\text { Dominant negative CLOCK } \\
\text { mutant animals show } \\
\text { lengthened of free running } \\
\text { period and arrhythmicity in } \\
\text { the dark }{ }^{15}\end{array}$ & $\begin{array}{l}\text { Mutant mouse models only } \\
\text { Disruption of BP regulation } \\
\text { during the light phase }{ }^{13} \\
\text { Disruption of HR during the } \\
\text { dark phase } \\
\text { Increased development of }^{13} \\
\text { atherosclerosis through } \\
\text { hypercholesterolaemia and } \\
\text { reduced cholesterol efflux from } \\
\text { macrophages }^{16}\end{array}$ \\
\hline $\begin{array}{l}\text { Neuronal PAS } \\
\text { domain-containing } \\
\text { protein } 2\end{array}$ & NPAS2 & $\begin{array}{l}\text { Can heterodimerize with } \\
B M A L I \text { in the absence of } \\
\text { CLOCK }\end{array}$ & Similar to CLOCK knockout ${ }^{14}$ & $\begin{array}{l}\text { Reduced HR and BP compared } \\
\text { to } W T^{\prime 3}\end{array}$ \\
\hline Period genes & Perl, Per2, Per3 & $\begin{array}{l}\text { Perl and Per2 allow resetting } \\
\text { of the central clock } \\
\text { Heterodimerize with Cry } \\
\text { genes to negatively regulate } \\
\text { BMALI/CLOCK }\end{array}$ & $\begin{array}{l}\text { Perl mutants are unable to } \\
\text { advance their clock } \\
\text { Per2 mutants do not delay } \\
\text { their clock } \\
\text { Combined loss of Perl and } \\
\text { Per2 results in immediate } \\
\text { arrhythmicity } 17\end{array}$ & $\begin{array}{l}\text { Perl: reduction in } \mathrm{BP}^{18} \\
\text { Per2: increased susceptibility to } \\
\text { myocardial ischaemic injury }{ }^{19} \\
\text { Per2: endothelial dysfunction } \\
\text { through reduced NO release }{ }^{20}\end{array}$ \\
\hline $\begin{array}{l}\text { Cryptochrome } \\
\text { genes }\end{array}$ & Cryl, Cry2 & $\begin{array}{l}\text { Heterodimerizes with Per } \\
\text { genes to negatively regulate } \\
\text { BMALI/CLOCK }\end{array}$ & $\begin{array}{l}\text { Cryl: accelerated free } \\
\text { running periodicity } \\
\text { Cry2: delayed free running } \\
\text { periodicity } \\
\text { Combined loss results in } \\
\text { immediate and complete loss } \\
\text { of free running periodicity }\end{array}$ & $\begin{array}{l}\text { Cryl/2: loss of diurnal variation } \\
\text { of } \mathrm{BP}^{21}\end{array}$ \\
\hline $\begin{array}{l}\text { Peroxisome } \\
\text { proliferator- } \\
\text { activated receptor } \\
\text { alpha }\end{array}$ & PPAR $\alpha$ & $\begin{array}{l}\text { Direct regulator of } \\
B M A L I^{12,22}\end{array}$ & None & $\begin{array}{l}\text { Reduced myocardial function } \\
\text { and myocardial fibrosis }{ }^{23}\end{array}$ \\
\hline $\begin{array}{l}\text { Peroxisome } \\
\text { proliferator- } \\
\text { activated receptor } \\
\text { gamma }\end{array}$ & PPAR $\gamma$ & Direct regulator of $B M A L I^{24}$ & $\begin{array}{l}\text { Loss of locomotor and } \\
\text { feeding rhythmicity }{ }^{24}\end{array}$ & $\begin{array}{l}\text { Loss of diurnal variation of } B P \\
\text { and } H R^{24}\end{array}$ \\
\hline
\end{tabular}

AKT: protein kinase B; eNOS: endothelial nitric oxide synthase; BP: blood pressure; HR: heart rate.

therefore not be directly applicable to humans since there are some major differences between rodents and humans regarding circadian rhythm (e.g. mice are night active). Furthermore, there are special cases regarding rodents such as hibernation in which case the circadian clock has been shown to stop functioning in some rodents. ${ }^{32}$ However, many of the genes involved in the animal clock mechanism (Per1, Per2, Clock, Bmall) have been described in humans and animal studies and therefore allow some conclusions to be drawn on human mechanisms. ${ }^{33}$

\section{$B M A L$}

It was shown that not only cardiomyocytes but also vascular smooth muscle cells (VSMCs) continue to exhibit a diurnal variation in gene expression even when the central clock is removed. ${ }^{34}$ Indeed, already some time ago, Keskil 


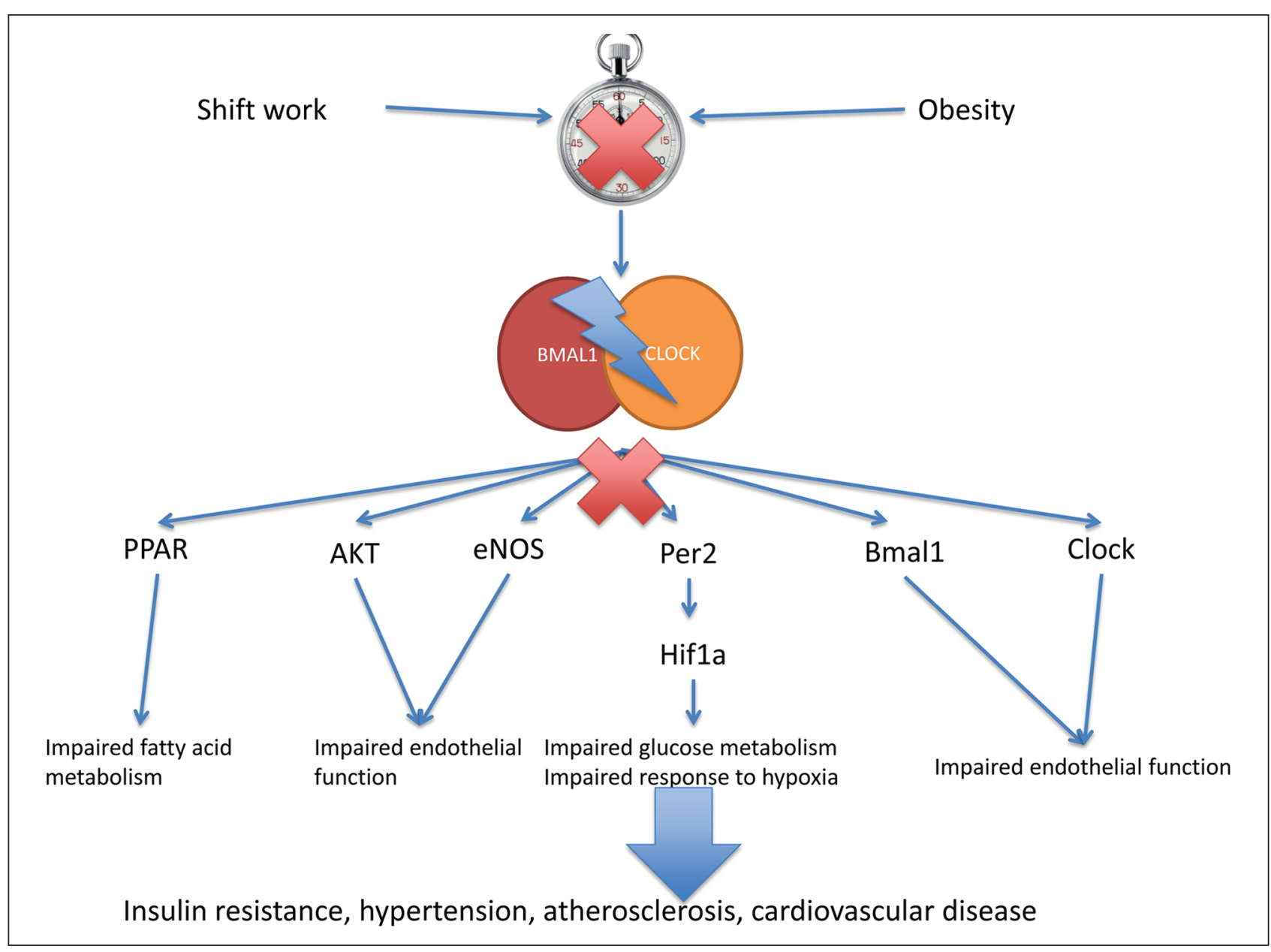

Figure 2. Schematic representation of the effects of circadian dyssynchrony on cardiometabolic function. Impairment of the central or peripheral clock, their dissynchrony or interference with either Bmall or Clock gene expression has been shown in vivo in mouse models to interfere with multiple different signalling axes and thus resulting in cardiometabolic dysfunction. PPAR: peroxisome proliferator-activated receptor; AKT: protein kinase B; eNOS: endothelial nitric oxide synthase; Per2: period homologue 2; Hifla: hypoxia-inducible factor I-alpha; BmalI: brain and muscle ARNT-like protein-I; Clock: circadian locomotor output cycles kaput.

et al..$^{35}$ showed that aortas taken from rats at different time points showed differing responsiveness to vasoactive agents. McNamara et al. ${ }^{36}$ then went on to show that VSMCs continue to exhibit rhythmic oscillation of Bmal1 and Per2 expression when kept in culture. Further investigations into the role of clock genes regarding VSMCs and endothelial dysfunction were carried out by Rudic et al. who investigated the effect of dysfunctional clock genes on the development of vascular diseases. Bmal1-/- and clock mutant mice were analysed, and the authors found that both exhibit pathological response to vascular injury which was, in part, shown to be due to impairment of the protein kinase B (AKT)-endothelial nitric oxide synthase (eNOS) axis leading to endothelial dysfunction (Figure 2). ${ }^{11}$ The results were confirmed by the same group using a transplant vasculopathy model which revealed that transplantation of a carotid artery from Bmal1-/- to wild type (WT) leads to an increase in arteriosclerosis, while such an effect is absent when a WT artery is transplanted into a Bmal1-/- mouse ${ }^{37}$ (Figure 3).

\section{CLOCK}

CLOCK total body knockout mice (Clock-/-) have been found to show no disturbances of circadian rhythm because neuronal PAS domain-containing protein 2 (NPAS2) can substitute for CLOCK deficiency by interacting with Bmal1. ${ }^{38}$ However, by deleting the exon 19 of the CLOCK gene $\left(\mathrm{CLOCK}^{19 / 19}\right)$, the resultant mutant protein, acting as a dominant negative regulator, disrupts $C L O C K$ function. CLOCK $^{19 / 19}$ mice have been shown to exhibit modest hypertryglyceridaemia, hypercholesterolaemia, hyperglycaemia and hyperleptinaemia. ${ }^{39}$

The effect of CLOCK function loss on cholesterol metabolism and the development of atherosclerosis have recently been elucidated. Pan et al. ${ }^{16}$ found that $\mathrm{CLOCK}^{19}$ mutant protein increases atherosclerosis development in LDLR-/- as well as APOE-/- mice, on a western as well as a normal diet, by increasing plasma cholesterol levels as well as macrophage cholesterol handling. 


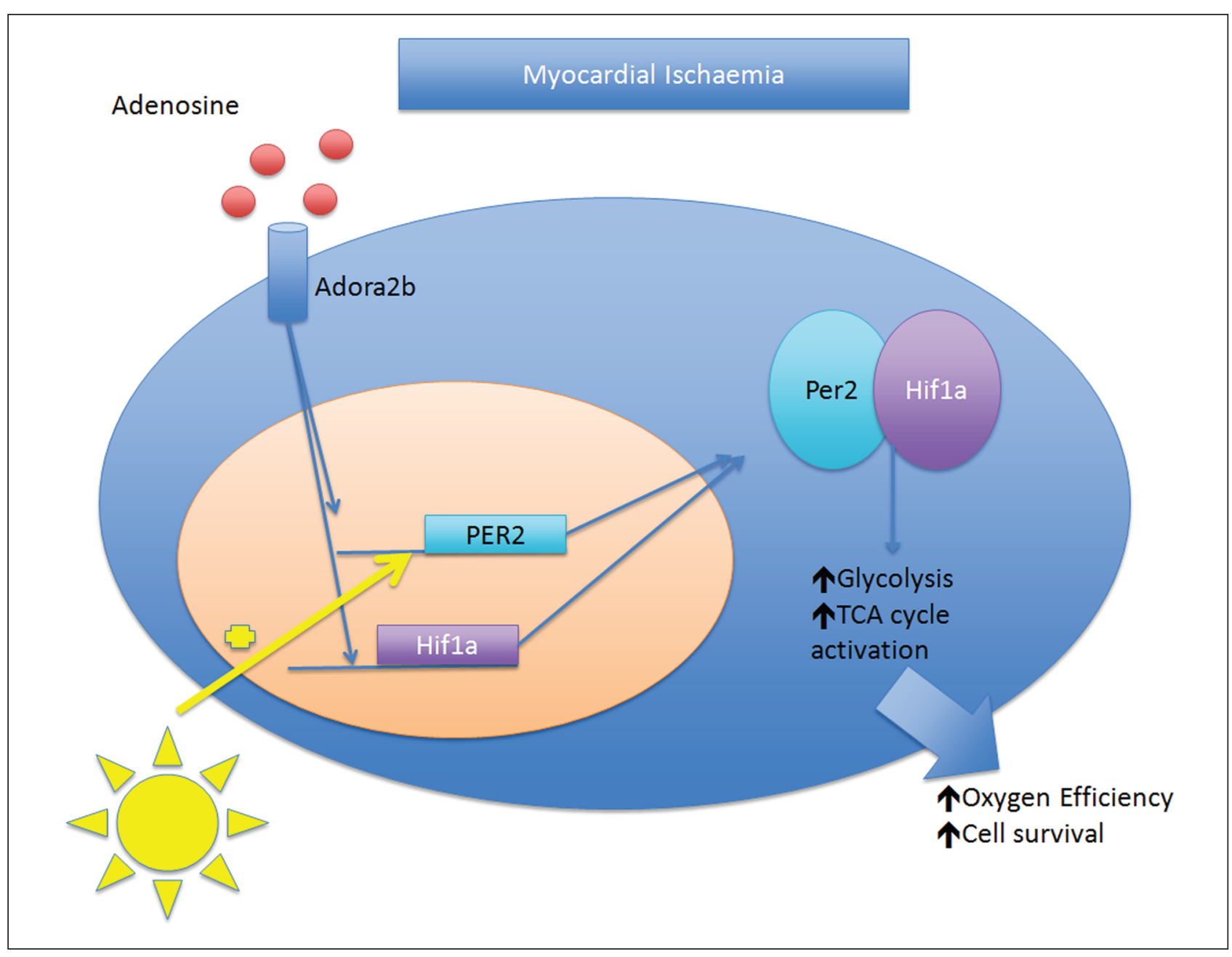

Figure 3. Per2 protects from ischaemic damage through activation of Hifla. Per2 activation through Adora2b confers protection from ischaemia-reperfusion injury in mice through Hifla activation resulting in increased glycolysis and thus increased oxygen efficiency. Per2: period homologue 2; Hifla: hypoxia-inducible factor I-alpha; Adora2b: adenosine A2b receptor; TCA: tricarboxylic acid.

Mechanistic studies revealed that the $\mathrm{CLOCK}^{19}$ protein enhances cholesterol absorption by enterocytes as well as the uptake of modified lipoproteins by macrophages in the hypercholesterolaemic mouse model ApoE. Furthermore, CLOCK $^{19}$ macrophages showed reduced reverse cholesterol transport associated with reduced levels of ATPbinding cassette ABCA1. By performing knockdown experiments in WT animals, the other studies showed that CLOCK directly regulates ABCA1 providing evidence that CLOCK dysregulation or dysfunction may directly influence lipid metabolism and macrophage function to enhance the development of atherosclerosis.

\section{Per2}

Mice with loss of Per2 function (Per2-/-) were shown to exhibit elevated circulating insulin levels and impaired glucose tolerance tests associated with enhanced glucose-stimulated insulin release and impaired insulin clearance. ${ }^{40}$
Initial investigation, gained from PAS domain mutant mice, into the role of Per2 suggested that this may be due to a propensity to develop defective feeding rhythm (increased daytime feeding), impaired glucocorticoid rhythm as well as overall hyperphagia. ${ }^{41}$ However, the model used in these studies did not represent a real loss of function model, and recent evidence has refuted earlier result by showing that whole-body knockout Per2 animals exhibit normal feeding and behavioural patterns. ${ }^{42}$

Further to the effects of Per2 on glucose metabolism, there has recently been compelling evidence suggesting that Per2 is able to directly influence lipid metabolism by interacting with PPAR $\gamma$ and repressing its transcriptional activity in white adipose tissue. Indeed, lipidomic analysis revealed an increase in the oxidation rate of FA in Per2-/mice, with a concomitant reduction in fat pad size and adipocyte diameter. ${ }^{42}$ Interestingly, the repressive activity of Per2 on PPAR $\gamma$ is different from its repression on the CLOCK:BMAL1 complex in that it is not only CRY independent but also tissue specific, being restricted to the 
WAT without any effects in the liver or brown adipose tissue. This underlines the likely existence of independent pathways of PER2 function, with a circadian clock-independent mechanism of repression of PPAR $\gamma$ as well as the circadian-dependent CLOCK:BMAL1 inhibition. ${ }^{42}$

The intimate involvement of Per2 and its role in cardiac metabolism during myocardial ischaemia were recently elucidated by Eckle et al. ${ }^{19}$ who showed that Per2 activation through adenosine receptor $\mathrm{A} 2 \mathrm{~b}$ (Adora2b) confers protection from ischaemia-reperfusion (I/R) injury in mice. The authors showed that during I/R, Per2-/- mice showed impaired glycolysis and thus impairment of the oxygen efficient pathway in the face of ischaemia, with increased uncoupling of glycolysis during the reperfusion suggesting mitochondrial dysfunction. The authors linked this effect to a Per2-dependent hypoxia-inducible factor 1-alpha (Hif1a) activation. Interestingly, Hifa1 displays a similar diurnal variation in the cardiac tissue as Per2. ${ }^{19}$

Hifla is a key transcriptional element in the glycolytic pathway as well as a strong response element protecting from hypoxia. ${ }^{43}$ Its activation has been shown to protect from ischaemia by increasing neovascularization through the upregulation of vascular endothelial growth factor and angiopoietin 1 and $2,{ }^{44}$ the recruitment of endothelial progenitor cells to the affected areas ${ }^{45}$ the preconditioning of tissue to ischaemic insults ${ }^{46}$ and the upregulation of glycolysis as an oxygen-sparing energy pathway. ${ }^{43}$

It was shown that infarction size in rodents varies according to daytime and that a high Hifla expression in the hours 12-18 (late evening) resulted in smaller infarction sizes. Thus, as discussed above, Per 2 expression may contribute to myocardial protection from ischaemia by upregulation of the oxygen efficient pathway of glucose utilization through the upregulation of Hifla.

\section{PPAR $\gamma$}

Further to its repression by Per2 in the WAT, there appears a role for PPAR $\gamma$ as a body-wide key integrator of molecular clocks. It was shown that PPAR $\gamma$ exhibits a strong diurnal variation, and in mice, altering the light/darkness cycle of the time of feeding can alter its expression. Mice lacking PPAR $\gamma$ in the vasculature develop disturbances in the diurnal variation of blood pressure (BP) and heart rate (HR) as well as a reduction in the variation in urinary norepinephrine/epinephrine excretions similar to that seen in Bmal1-/- mice. ${ }^{24}$ Indeed, animals fed Rosiglitazone, a PPAR $\gamma$ agonist, showed induction of Bmall in the aorta. There is some evidence that this is also applicable to humans as pioglitazone, another PPAR $\gamma$ agonist, can restore normal circadian variation of $\mathrm{BP} .{ }^{47}$

This phenotype was confirmed in animals with wholebody knockout of PPAR $\gamma$. These displayed a striking loss of rhythmicity, regarding not only HR and BP but also locomotor activity and feeding behaviour. Further to this,
PPAR $\gamma$ null mice also showed loss of peripheral circadian rhythmicity of gene expression patterns of clock genes (BMAL1, Per1, Per2, Per3, Cryl) in the liver and WAT. ${ }^{48}$

\section{PPAR $\alpha$}

PPAR $\alpha$ is part of the superfamily of nuclear receptors responsible for the regulation of lipid metabolism. Being sensitive to the availability of FAs, it is responsible for the heart's rapid ability to adapt to circulating energy substrates. ${ }^{49}$

For some time now, it has been known that the expression of PPAR $\alpha$ follows a diurnal rhythm in mice and rats. ${ }^{50}$ While this may, in part, be explained by the hormonal influence of glucocorticoids and insulin that directly affect transcriptional activity of $P P A R \alpha$, it has been shown that it is regulated in a clock-dependent manner in several peripheral tissues. ${ }^{51}$

The first evidence regarding the interaction between PPAR $\alpha$ and the clock mechanism came from the observation that obese mice, which lost weight, showed upregulation of PPAR $\alpha$ with a concomitant restoration of diurnal variation of HR and BP. ${ }^{52}$ Similarly, when diabetic patients were treated with fenofibrate, a PPAR $\alpha$ agonist, there was a marked antihypertensive effect at night that was not reflected in overall daytime BP. Furthermore, fenofibrate lowered the average HR over the whole $24-\mathrm{h}$ day, ${ }^{53}$ thus suggesting a potential direct link between PPAR $\alpha$ and the clock mechanism.

While PPAR $\alpha$ knockout mice (PPAR $\alpha-/-)$ were shown to exhibit normal circadian locomotor and unaffected $S C N$ clock gene expression, they do exhibit a loss of rhythmicity in the liver transcription profiles of Bmal1 and Per3.22 Conversely, fenofibrate, a PPAR $\alpha$ agonist, is able to upregulate the expression of Bmall in the liver suggesting a direct link between PPAR $\alpha$ levels and Bmall expression. Indeed, there appears to be a direct regulation of Bmall transcription by PPARas through its ability to bind to the promoter of Bmal1. At the same time, Bmal1-/- mice show a dysregulation of PPAR $\alpha$ rhythmicity demonstrating a feedback loop wherein PPAR $\alpha$ promotes Bmal1 transcription which in turn supplies a circadian regulation on PPAR $\alpha .{ }^{22}$

To summarize, we can say that while research into the exact mechanism in which clock genes interact with cardiovascular metabolism is still in its infancy, there is no denying that there is a definite link which will need to be explored further.

\section{Circadian clock and myocardial infarction}

The observation that myocardial infarctions are increased in the early hours of the morning was already made over 20 years ago. ${ }^{54} \mathrm{~A}$ meta-analysis by Cohen et al..$^{55}$ including 
over 60,000 acute myocardial infarction (AMI) patients showed a strongly increased incidence in the hours between 06:00 a.m. and midday. This increased mortality was previously mainly thought to be associated with increased sympathetic activity in the waking phase. Indeed, administration of a beta-blocker resulted in the loss of the morning excess of AMI. ${ }^{56}$ However, recent discoveries have shed a new light on this topic.

A perfect population to study the mechanism of clock disruption and its effects includes shift workers in whom the risk of developing obesity, ${ }^{57,58}$ diabetes ${ }^{59}$ or premature death is greatly increased. ${ }^{60}$ The circadian misalignment seen in this group has been shown to correlate with insulin resistance, cortisol derangements as well as increased BP. ${ }^{2}$

When examining the Swedish Registry for AMI which keeps accurate data of all AMI in Sweden since 1987, Janszky and Ljung ${ }^{61}$ found that the incidence of AMI is also increased in the first 3 days after the change from winter to summer time. On the contrary, rates of AMI were reduced when switching from summer to wintertime, which adds an hour of sleep. This trend was confirmed by Jiddou et al. ${ }^{62}$ in a retrospective study of 935 patients carried out between 2006 and 2012 in Michigan.

While the authors present some valid reasoning for this increased occurrence, including acute sleep deprivationinduced sympathetic predominance and catecholamine release, no single mechanism has been elucidated to date accounting for this phenomenon. ${ }^{63}$

The incidences of myocardial infarction as well as the onset of arrhythmias have also been shown to be increased during the switch from the sleep to the awake state. Several mechanisms in the heart confer protection from ischaemia, and the survival of ischaemic cardiomyocytes, in part, depends on the activation of these pathways. ${ }^{64}$ Intriguingly, rather than being constantly expressed, some of the proteins involved in these pathways appear to show a circadian dependence..$^{65}$ Durgan et al. ${ }^{66}$ recently showed that mice undergoing I/R injury at the sleep-to-wake transition exhibited greater infarction sizes than mice that underwent $\mathrm{I} / \mathrm{R}$ at the wake-to-sleep transition moment. These changes were abolished in animals with genetic ablation of the circadian clock in the cardiomyocytes. The authors linked this to the circadian variations in the phosphorylation of the pro-survival genes $A K T$ and $G S K-3 \beta$.

So far, very few groups have attempted to reproduce the animal data in humans, and the data obtained remain somewhat controversial. Suarez-Barrientos et al. ${ }^{65}$ retrospectively analysed 811 ST-elevation myocardial infarction (STEMI) patients admitted in a single centre in Spain. The authors found a clear association between time of day and incidence of ischaemic events and also infarction size as determined by peak creatine kinase and troponin I. In this patient group, infarction size was found to be larger in the patient group with onset of symptoms between 06:00 a.m. and noon.
Reiter et al. ${ }^{67}$ similarly retrospectively analysed 165 STEMI patients and found that myocardial injury was greatest at 01:00 a.m. onset of ischaemia and 05:00 a.m. onset of reperfusion, even when adjusted for area at risk as measured by cardiac magnetic resonance imaging (MRI) and angiographic assessment.

While there is a slight discrepancy between the data obtained regarding peak time of myocardial ischaemic damage, in part, probably due to Reiter et al. retrospectively excluding a large number of patients (around 85\%) rather than including and analysing all patients in an unbiased way and then adjusting for potential bias, the clear trend regarding daytime-dependent myocardial injury size appears obvious.

However, earlier this year, Ammirati et al. ${ }^{68}$ through the retrospective analysis of data from the First Acute Myocardial Infarction (FAMI) study, carried out between 2002 and 2007 in three different countries (Italy, China and Scotland), while confirming the increased incidence of myocardial infarction in the early hours of the morning, were unable to reproduce the effect of time of day on infarction size seen by Suarez-Barrientos et al. and Reiter et al. despite multiple statistical models.

The ambiguousity of these results shows that more research into the exact molecular mechanisms underlying infarction size and daytime will need to be carried out.

\section{Perspectives}

Taken together, these data suggest that disturbance of the circadian clock may not only contribute to metabolic changes such as insulin resistance and diabetes but also may directly influence $\mathrm{CV}$ risk and the occurrence of cardiovascular events. However, a better understanding of the underlying molecular mechanisms is needed for the development of diagnostic and eventually therapeutic strategies. What we are lacking are, however, reliable markers to estimate how the lifestyle is impacting on circadian regulation. Investigating subjects with a misaligned circadian rhythm such as shift workers may lead to the identification of novel biomarkers of the disturbed clock system and thus help us to gain more insight into the role of the circadian clock in the cardiovascular system.

\section{Declaration of conflicting interests}

The authors declare no conflicts of interest.

\section{Funding}

This work was funded, in part, by FP-7 EURHYTHDIA, Fondazione Roma 2008, ESFD/Lilly 2012, AIRC 2012 Project IG 13163, FP7-Health-241913 FLORINASH, PRIN 2009FATXW3_002 and SID Grant 2013 to Massimo Federici. Robert Stöhr was supported by a fellowship from the Deutsche Herzstiftung and the University of Rome Tor Vergata. 


\section{References}

1. European Society of Cardiology (ESC). European cardiovascular disease statistics, http://www.escardio.org/about/ documents/eu-cardiovascular-disease-statistics-2012.pdf (2012).

2. Scheer FA, Hilton MF, Mantzoros CS, et al. Adverse metabolic and cardiovascular consequences of circadian misalignment. Proc Natl Acad Sci USA 2009; 106: 4453-4458.

3. Feng D and Lazar MA. Clocks, metabolism, and the epigenome. Mol Cell 2012; 47: 158-167.

4. Stokkan KA, Yamazaki S, Tei H, et al. Entrainment of the circadian clock in the liver by feeding. Science 2001; 291: 490-493.

5. Dibner C, Schibler U and Albrecht U. The mammalian circadian timing system: organization and coordination of central and peripheral clocks. Annu Rev Physiol 2010; 72: 517-549.

6. Balsalobre A, Brown SA, Marcacci L, et al. Resetting of circadian time in peripheral tissues by glucocorticoid signaling. Science 2000; 289: 2344-2347.

7. Hogenesch JB, Gu YZ, Jain S, et al. The basic-helix-loophelix-PAS orphan MOP3 forms transcriptionally active complexes with circadian and hypoxia factors. Proc Natl Acad Sci USA 1998; 95: 5474-5479.

8. Gekakis N, Staknis D, Nguyen HB, et al. Role of the CLOCK protein in the mammalian circadian mechanism. Science 1998; 280: 1564-1569.

9. Lee C, Etchegaray JP, Cagampang FR, et al. Posttranslational mechanisms regulate the mammalian circadian clock. Cell 2001; 107: 855-867.

10. Bunger MK, Wilsbacher LD, Moran SM, et al. Mop3 is an essential component of the master circadian pacemaker in mammals. Cell 2000; 103: 1009-1017.

11. Anea CB, Zhang M, Stepp DW, et al. Vascular disease in mice with a dysfunctional circadian clock. Circulation 2009; 119: 1510-1517.

12. Anea CB, Cheng B, Sharma $\mathrm{S}$, et al. Increased superoxide and endothelial NO synthase uncoupling in blood vessels of Bmal1-knockout mice. Circ Res 2012; 111: 1157-1165.

13. Curtis AM, Cheng Y, Kapoor S, et al. Circadian variation of blood pressure and the vascular response to asynchronous stress. Proc Natl Acad Sci USA 2007; 104: 3450-3455.

14. DeBruyne JP, Weaver DR and Reppert SM. Peripheral circadian oscillators require CLOCK. Curr Biol 2007; 17: R538-R539.

15. Vitaterna MH, King DP, Chang AM, et al. Mutagenesis and mapping of a mouse gene, Clock, essential for circadian behavior. Science 1994; 264: 719-725.

16. Pan X, Jiang XC and Hussain MM. Impaired cholesterol metabolism and enhanced atherosclerosis in clock mutant mice. Circulation 2013; 128: 1758-1769.

17. Albrecht U, Zheng B, Larkin D, et al. MPer1 and mper2 are essential for normal resetting of the circadian clock. J Biol Rhythms 2001; 16: 100-104.

18. Stow LR, Richards J, Cheng KY, et al. The circadian protein period 1 contributes to blood pressure control and coordinately regulates renal sodium transport genes. Hypertension 2012; 59: 1151-1156.

19. Eckle T, Hartmann K, Bonney S, et al. Adora2b-elicited Per2 stabilization promotes a HIF-dependent metabolic switch crucial for myocardial adaptation to ischemia. Nat Med 2012; 18: 774-782.

20. Viswambharan H, Carvas JM, Antic V, et al. Mutation of the circadian clock gene Per2 alters vascular endothelial function. Circulation 2007; 115: 2188-2195.

21. Masuki S, Todo T, Nakano Y, et al. Reduced alpha-adrenoceptor responsiveness and enhanced baroreflex sensitivity in Cry-deficient mice lacking a biological clock. J Physiol 2005; 566: 213-224.

22. Canaple L, Rambaud J, Dkhissi-Benyahya O, et al. Reciprocal regulation of brain and muscle Arnt-like protein 1 and peroxisome proliferator-activated receptor alpha defines a novel positive feedback loop in the rodent liver circadian clock. Mol Endocrinol 2006; 20: 1715-1727.

23. Loichot C, Jesel L, Tesse A, et al. Deletion of peroxisome proliferator-activated receptor-alpha induces an alteration of cardiac functions. Am J Physiol Heart Circ Physiol 2006; 291: H161-H166.

24. Wang N, Yang G, Jia Z, et al. Vascular PPARgamma controls circadian variation in blood pressure and heart rate through Bmal1. Cell Metab 2008; 8: 482-491.

25. Rudic RD, McNamara P, Curtis AM, et al. BMAL1 and CLOCK, two essential components of the circadian clock, are involved in glucose homeostasis. PLoS Biol 2004; 2: e377.

26. Lamia KA, Storch KF and Weitz CJ. Physiological significance of a peripheral tissue circadian clock. Proc Natl Acad Sci USA 2008; 105: 15172-15177.

27. Carvas JM, Vukolic A, Yepuri G, et al. Period2 gene mutant mice show compromised insulin-mediated endothelial nitric oxide release and altered glucose homeostasis. Front Physiol 2012; 3: 337.

28. Stanley WC, Recchia FA and Lopaschuk GD. Myocardial substrate metabolism in the normal and failing heart. Physiol Rev 2005; 85: 1093-1129.

29. Heineman FW and Balaban RS. Control of mitochondrial respiration in the heart in vivo. Annu Rev Physiol 1990; 52: 523-542.

30. Balaban RS, Kantor HL, Katz LA, et al. Relation between work and phosphate metabolite in the in vivo paced mammalian heart. Science 1986; 232: 1121-1123.

31. Young ME, Razeghi P, Cedars AM, et al. Intrinsic diurnal variations in cardiac metabolism and contractile function. Circ Res 2001; 89: 1199-1208.

32. Revel FG, Herwig A, Garidou ML, et al. The circadian clock stops ticking during deep hibernation in the European hamster. Proc Natl Acad Sci USA 2007; 104: 13816-13820.

33. Cermakian N and Boivin DB. A molecular perspective of human circadian rhythm disorders. Brain Res Brain Res Rev 2003; 42: 204-220.

34. Rudic RD, Curtis AM, Cheng Y, et al. Peripheral clocks and the regulation of cardiovascular and metabolic function. Methods Enzymol 2005; 393: 524-539.

35. Keskil Z, Görgün CZ, Hodoğlugil U, et al. Twenty-fourhour variations in the sensitivity of rat aorta to vasoactive agents. Chronobiol Int 1996; 13: 465-475.

36. McNamara P, Seo SB, Rudic RD, et al. Regulation of CLOCK and MOP4 by nuclear hormone receptors in the vasculature: a humoral mechanism to reset a peripheral clock. Cell 2001; 105: 877-889. 
37. Cheng B, Anea CB, Yao L, et al. Tissue-intrinsic dysfunction of circadian clock confers transplant arteriosclerosis. Proc Natl Acad Sci USA 2011; 108: 17147-17152.

38. Debruyne JP, Noton E, Lambert CM, et al. A clock shock: mouse CLOCK is not required for circadian oscillator function. Neuron 2006; 50: 465-477.

39. Turek FW, Joshu C, Kohsaka A, et al. Obesity and metabolic syndrome in circadian Clock mutant mice. Science 2005; 308: 1043-1045.

40. Zhao Y, Zhang Y, Zhou M, et al. Loss of mPer2 increases plasma insulin levels by enhanced glucose-stimulated insulin secretion and impaired insulin clearance in mice. FEBS Lett 2012; 586: 1306-1311.

41. Yang S, Liu A, Weidenhammer A, et al. The role of mPer2 clock gene in glucocorticoid and feeding rhythms. Endocrinology 2009; 150: 2153-2160.

42. Grimaldi B, Bellet MM, Katada S, et al. PER2 controls lipid metabolism by direct regulation of PPARgamma. Cell Metab 2010; 12: 509-520.

43. Ratcliffe PJ. From erythropoietin to oxygen: hypoxia-inducible factor hydroxylases and the hypoxia signal pathway. Blood Purif 2002; 20: 445-450.

44. Semenza GL. Angiogenesis in ischemic and neoplastic disorders. Annu Rev Med 2003; 54: 17-28.

45. Ceradini DJ, Kulkarni AR, Callaghan MJ, et al. Progenitor cell trafficking is regulated by hypoxic gradients through HIF-1 induction of SDF-1. Nat Med 2004; 10: 858-864.

46. Date T, Mochizuki S, Belanger AJ, et al. Expression of constitutively stable hybrid hypoxia-inducible factor-1alpha protects cultured rat cardiomyocytes against simulated ischemia-reperfusion injury. Am J Physiol Cell Physiol 2005; 288: C314-C320.

47. Anan F, Masaki T, Fukunaga N, et al. Pioglitazone shift circadian rhythm of blood pressure from non-dipper to dipper type in type 2 diabetes mellitus. Eur J Clin Invest 2007; 37 : 709-714.

48. Yang G, Jia Z, Aoyagi T, et al. Systemic PPARgamma deletion impairs circadian rhythms of behavior and metabolism. PLoS One 2012; 7: e38117.

49. Barger PM and Kelly DP. PPAR signaling in the control of cardiac energy metabolism. Trends Cardiovasc Med 2000; 10: $238-245$.

50. Lemberger T, Saladin R, Vázquez M, et al. Expression of the peroxisome proliferator-activated receptor alpha gene is stimulated by stress and follows a diurnal rhythm. $J$ Biol Chem 1996; 271: 1764-1769.

51. Oishi K, Shirai H and Ishida N. CLOCK is involved in the circadian transactivation of peroxisome-proliferator-activated receptor alpha (PPARalpha) in mice. Biochem J 2005; 386: 575-581.

52. Verreth W, De Keyzer D, Pelat M, et al. Weight-lossassociated induction of peroxisome proliferator-activated receptor-alpha and peroxisome proliferator-activated receptor-gamma correlate with reduced atherosclerosis and improved cardiovascular function in obese insulin-resistant mice. Circulation 2004; 110: 3259-3269.
53. Chew GT, Watts GF, Davis TM, et al. Hemodynamic effects of fenofibrate and coenzyme Q10 in type 2 diabetic subjects with left ventricular diastolic dysfunction. Diabetes Care 2008; 31: 1502-1509.

54. Muller JE, Tofler GH and Stone PH. Circadian variation and triggers of onset of acute cardiovascular disease. Circulation 1989; 79: 733-743.

55. Cohen MC, Rohtla KM, Lavery CE, et al. Meta-analysis of the morning excess of acute myocardial infarction and sudden cardiac death. Am J Cardiol 1997; 79: 1512-1516.

56. Willich SN, Linderer $\mathrm{T}$, Wegscheider $\mathrm{K}$, et al. Increased morning incidence of myocardial infarction in the ISAM Study: absence with prior beta-adrenergic blockade. ISAM Study Group. Circulation 1989; 80: 853-858.

57. Di Lorenzo L, De Pergola G, Zocchetti C, et al. Effect of shift work on body mass index: results of a study performed in 319 glucose-tolerant men working in a Southern Italian industry. Int J Obes Relat Metab Disord 2003; 27: 13531358.

58. Kubo T, Oyama I, Nakamura T, et al. Industry-based retrospective cohort study of the risk of prostate cancer among rotating-shift workers. Int J Urol 2011; 18: 206-211.

59. Nagaya T, Yoshida H, Takahashi H, et al. Markers of insulin resistance in day and shift workers aged $30-59$ years. Int Arch Occup Environ Health 2002; 75: 562-568.

60. Huang W, Ramsey KM, Marcheva B, et al. Circadian rhythms, sleep, and metabolism. J Clin Invest 2011; 121: 2133-2141.

61. Janszky I and Ljung R. Shifts to and from daylight saving time and incidence of myocardial infarction. $N$ Engl J Med 2008; 359: 1966-1968.

62. Jiddou MR, Pica M, Boura J, et al. Incidence of myocardial infarction with shifts to and from daylight savings time. Am J Cardiol 2013; 111: 631-635.

63. Zhong X, Hilton HJ, Gates GJ, et al. Increased sympathetic and decreased parasympathetic cardiovascular modulation in normal humans with acute sleep deprivation. $J$ Appl Physiol 2005; 98: 2024-2032.

64. Hausenloy DJ and Yellon DM. New directions for protecting the heart against ischaemia-reperfusion injury: targeting the Reperfusion Injury Salvage Kinase (RISK)-pathway. Cardiovasc Res 2004; 61: 448-460.

65. Suarez-Barrientos A, López-Romero P, Vivas D, et al. Circadian variations of infarct size in acute myocardial infarction. Heart 2011; 97: 970-976.

66. Durgan DJ, Pulinilkunnil T, Villegas-Montoya C, et al. Short communication: ischemia/reperfusion tolerance is time-of-day-dependent: mediation by the cardiomyocyte circadian clock. Circ Res 2010; 106: 546-550.

67. Reiter R, Swingen C, Moore L, et al. Circadian dependence of infarct size and left ventricular function after ST elevation myocardial infarction. Circ Res 2012; 110: 105-110.

68. Ammirati E, Cristell N, Cianflone D, et al. Questing for circadian dependence in ST-segment-elevation acute myocardial infarction: a multicentric and multiethnic study. Circ Res 2013; 112: e110-e114. 